\title{
O silêncio como estratégia para o diálogo em "Silence" da obra Vastafala, de Antonio Barreto
}

\section{Silence as a strategy for dialogue in "Silence" of the work Vastafala, by Antonio Barreto}

\author{
Guaraciaba Micheletti ${ }^{1}$ \\ Janusa Guimarães Gomez ${ }^{2}$
}

\begin{abstract}
Resumo: Este artigo versará sobre os resultados obtidos por meio da análise do poema "Silence", parte integrante do livro Vastafala, de Antonio Barreto. Investigamos, nesse texto literário, os recursos utilizados pelo sujeito poético cujo objetivo é promover o diálogo evocando a necessidade intrínseca do ser humano que é expressar-se e comunicar-se. Numa aparente ação paradoxal, ele coloca condições para emergência do diálogo. O enunciador de "Silence" espera estabelecer um contato com seu interlocutor por meio de "conversaremos", explorando várias possibilidades do léxico. A fundamentação teórica que norteou esta análise e interpretação foram os estudos de Martins (2012) que tratam da Estilística e apontam quais estratos devem ser verificados nesse tipo de estudo: o som, a palavra, a sintaxe, os desdobramentos dessas três camadas e aspectos enunciativos; as referências bibliográficas se expandem para Orlandi (2015), que aborda as questões da significação do silêncio, Garcia (2011) cujo propósito seja a comunicação em prosa atentando para "moderna" sobre a estrutura sintática e a feição estilística da frase e Bechara (2009), cujos estudos focalizam a gramática normativa.
\end{abstract}

Palavras-chave: Poema; Vastafala; Estilística; Silêncio; Diálogo.

Abstract: This article will focus on the results obtained by analyzing the poem "Silence", an integral part of the book Vastafala, by Antonio Barreto. We investigate, in this literary text, the resources used by the poetic subject whose goal is to promote dialogue by evoking the intrinsic need of the human being to express and communicate. In an apparent paradoxical action, it poses conditions for the emergence of dialogue. The enunciator of "Silence" hopes to establish contact with his interlocutor by means of " we'll talk", exploring several possibilities of the lexicon. The basic theoretical basis for this analysis and interpretation was the Martins (2012) which deals with stylistics and indicates which strata should be verified in this type of study: sound, word, syntax, unfolding of these three layers and enunciative aspects; the bibliographic references expand to Orlandi (2015), which addresses the issues of the significance of silence; Garcia (2011), whose purpose is to communicate in prose considering "modern" about the syntactic structure and the stylistic feature of the frase and Bechara (2009), whose studies focus on normative grammar.

Keywords: Poem; "Vastafala"; Stylistics; Silence; Dialogue

1 Dra. em Letras (Teoria Literária e Literatura Comparada) pela Universidade de São Paulo - USP. Coordenadora e orientadora do programa de pós-graduação Mestrado em Linguística da Universidade Cruzeiro do Sul - UNICSUL. Professora aposentada da USP. E-mail: guatti@uol.com.br

2 Mestranda em Linguística, vinculada à linha de pesquisa Estilística gramática e estilo, da Universidade Cruzeiro do Sul - UNICSUL, orientanda da professora Dra. Guaraciaba Micheletti. E-mail: janggomez@gmail.com 


\section{Considerações iniciais}

Antonio Barreto lançou em 1988 seu segundo livro, Vastafala, dez anos após o primeiro, O sono provisório. Nascido em Passos, interior de Minas, aos quatorze anos migrou para Belo Horizonte com a intenção de tornar-se jogador de futebol. Embora tenha logrado bons resultados como esportista, suas "composições", como eram chamadas as redações naquele tempo, ficaram conhecidas entre colegas e professores, e a vocação para a escrita literária ganhava força a cada poema que era publicado no jornal da escola; de forma despretensiosa nascia um poeta.

Iniciou os cursos de História e Letras, pois entendia que os conhecimentos provenientes desses estudos o ajudariam na saga de escritor, mas, em suas palavras, "por artes da sobrevivência"³ tornou-se projetista de construção civil e, por meio desta formação, no início da década de 80, trabalhou abrindo estradas, construindo pontes e edifícios no Iraque, cenário recorrente em algumas de suas produções literárias.

Seu trabalho como escritor não termina em Vastafala, Barreto publicou diversas obras em diferentes gêneros literários como poemas ${ }^{4}$, literatura infantil ${ }^{5}$ e romance ${ }^{6}$, tornando-se um escritor eclético ${ }^{7}$. Como poeta, recebeu diversos primeiros lugares em Concurso Literários ${ }^{8}$, incluindo Vastafala que levou, entre outros, o Prêmio Bienal Nestlé de Literatura Brasileira em 1988.

Alguns poemas de Vastafala, entre eles, "Silence", foco desta análise, constituem o corpus do projeto de Mestrado desta pesquisadora, e está inserido na Linha de Pesquisa: Estudos estilísticos: discurso, gramática e estilo que tem buscado novas formas de análise e interpretação por meio do que se denomina "Estilística discursivo-textual".

A fundamentação teórica básica principia pelos estudos de Martins (2012) que trata dos estudos Estilísticos e aponta quais estratos devem ser verificados nesse tipo de estudo: o som, a palavra, a sintaxe, os desdobramentos dessas três camadas e aspectos enunciativos.

\footnotetext{
3 Breve biografia escrita em primeira pessoa, na página de divulgação do livro Vagalovnis, no site da editora Autêntica. Disponível em: https://grupoautentica.com.br/autentica-infantil-e-juvenil/autor/antonio-barreto/794. Acesso em 23/02/2018.

4 Alguns: “Orquestra bichofônica”, 2013, “Isca de pássaro é peixe na gaiola”, 2013.

5 Podemos citar: Lua no Varal editora Miguilim e Vagalovnis, 2011.

6 Como: "A guerra dos parafusos", 2017 "O homem que sabia javanês" releitura do homônimo de Lima Barreto. Atual editora, 1922.

7 Barreto também enveredou na literatura infanto-juvenil com "O livro das simpatias". Editora Boabá, 2014, Contos como "O centro" da coleção "BH a cidade de cada um", editora conceito editorial, 2014, e Crônicas como "O papagaio de Van Gogh", 2013

8 Prêmio (P) (Câmara Brasileira do Livro), Bolsa Vitae de Literatura, P. Remington, Bienal Nestlé de Literatura, P. Minas de Cultura, P. Nacional de Contos do Paraná, P. "Guimarães Rosa" de romance, P. "Emílio Moura" de poesia, P. "Cidade de Belo Horizonte" - poesia e contos, P. "João-de-Barro" de literatura infantil e juvenil , P. "Carlos Drummond de Andrade" e "Manuel Bandeira” de poesia, UBE (SP, PE, RJ); Prêmio "Henriqueta Lisboa", P. "Petrobrás" de Literatura, P. Nacional de Literatura/UFMG, P. Bienal do Livro de BH, P. Bienal Internacional do Livro de SP, P. de "Leitura Altamente Recomendável” para crianças e jovens/FNLIJ-RJ, P. "Tereza Martin" de Literatura, P. Internacional da Paz/Poesia (ONU), P. "Ezra Jack Keats" da Unesco/Unicef (EUA), P./ Obras/Catálogo do IBBY (Unesco) e P./Obras/Catálogos Bienais Internacionais do Livro de Bratislava, Barcelona, Bolonha, Frankfurt e Cidade do México.
} 


\section{Introdução}

Sempre que o leitor procede à leitura de um texto, busca algum tipo de elo para que o processo flua, para além da compreensão advinda de um primeiro contato com o texto. Essa busca o faz ir além, buscando o sentido que se oculta entre palavras, figuras de linguagem e elementos sonoros.

O silêncio é o tema central do poema "Silence" e, embora essa palavra apareça apenas no título, sua significação envolve todo o movimento que se apresenta na tessitura do poema.

Em "Silence", que faz parte de um grupo de poemas a que o autor denominou "Garganta didática", em seu livro Vastafala, nos deparamos com uma necessidade de expressão e comunicação. Esse expressar e comunicar-se se faz pela fala e pelo silêncio. Essas ações não se fazem apenas pela palavra (ou por gestos), mas também, como afirma Orlandi, pelo "o silêncio (que) é a matéria significante por excelência" (2015, p. 29).

O sujeito poético de "Silence" trata dessa necessidade intrínseca do homem que sempre dialoga, fala, discursa focado em um ouvinte, e até consigo mesmo. Sua pretensão é atingir o outro, representado em alguns versos de seu discurso, pela segunda pessoa do singular, mas quase sempre associado a esse sujeito poético pelo uso da primeira pessoa do plural. Percebe-se, desde o início da leitura, uma espécie de jogo entre o silêncio e a fala.

O título do poema escrito em outro idioma (que tanto pode ser inglês como francês), não prejudica o entendimento do significado da palavra. Por ser um cognato, logo compreendemos que "Silence" refere-se a Silêncio que pode ser entendido como ausência de som, quietude. Entretanto a própria existência do poema estabelece uma dualidade.

Em aparente contradição, há, em "Silence", o excesso de fala, uma vez que o eu lírico discorre sobre um tempo e circunstâncias para que haja uma conversa. Esse tempo fica demarcado pelos versos que constituem uma explanação minuciosa das condições favoráveis a um diálogo, ou seja, não há verdadeiramente um silêncio. "Silence" como título em contraste com o desenvolvimento do poema soa paradoxal, uma vez que se apresentam reiteradamente as condições para a erupção de um diálogo e, nos versos finais das estrofes um e três, tem-se a afirmação: "conversaremos".

Como já foi mencionado, a única aparição da palavra silêncio consta no título (silence), o que conduz a algumas indagações: a que silêncio o sujeito poético se refere? Ou, por qual razão ele pede que se faça silêncio? Ou, ainda, a suposição de que haverá silêncio até que algumas exigências sejam satisfeitas. Assim, pode-se inferir que o eu lírico não pede silêncio, na verdade, anseia quebrá-lo, pois ele é quem determina um tempo/situação favorável para que haja diálogo.

Observando a apresentação dos versos, é possível notar o recuo constante de um espaço, correspondente a uma letra, a cada novo verso do poema, sugerindo afastamento ou avanço, progressão; verificamos esse efeito principalmente nas estrofes um e dois, que se apresentam muito semelhantes, com sete e oito versos, nessa ordem.

Diferente do que acontece com as duas últimas que são curtas, com três e quatro versos, respectivamente, e se apresentam não mais como um elenco de condições, mas, na qualidade de conclusão, uma espécie de retomada e fecho do que foi expresso nas duas primeiras estrofes, com o mesmo recuo sutil nos versos subsequentes ao primeiro de cada estrofe. Consideramos, ainda, que os 
versos dessas duas estrofes são menores, não há mais expansão, mas uma síntese, que ao final é o silêncio.

Observemos mais de perto o poema:

Silence

Quando disparar no peito o ritmo dos séculos

Quando pernoitar nos olhos um galo e sua aurora

Quando todavia nos faltarem copos e garrafas

Quando despertarem as pedras que escondemos nas mãos

Quando o estado em mim, das coisas e dos ritos

em ti, bovinamente, em geral ficarem,

conversaremos.

Quando o sangue reservar o corpo todo

Quando a ferrugem das veias exigir mais tempo

e o rio de nós engordar o coração e o chão

de todas as coisas não for pisado novamente

Quando o ócio dos nocautes vier em chuva e enxurrada

e a própria chuva rir e dividir o nosso nada

Quando fizermos epígrafes para os tontos

e conspirarmos contra a respiração dos muros

E em ti faltar o fôlego das nuvens

e das águas,

conversaremos.

Sobre tudo isso erigiremos estátuas,

Submersos e amigos

e talvez

cabisbaixos.

"Silence" é dedicado a Sérgio e Suzana Nunes de Moraes $^{9}$ e, embora haja pouca informação sobre eles, além da nota ao final do livro. A dedicatória é representada ao lado do título de forma inusual, apenas por um número que identificará os destinatários somente no final do livro, numa espécie de anexo, sob o título singular, "Créditos e/ ou averiguações intertextuais do subconsciente coletivo \& um final infame". Não nos deteremos na questão da dedicatória, ainda que apresentada de modo original, pelo foco do artigo serem os recursos linguísticos existentes nos versos do poema.

9 “Para Sérgio e Suzana Nunes de Moraes, a forma e a cor, o poema e seu necessário silêncio estapafúrdio." (BARRETO, A. Vastafala. São Paulo. Scipione. 1988. p. 123) 
De início, a atenção do leitor é atraída por dois aspectos: um, visual, a distribuição das estrofes e dos versos na página; outro, o paralelismo que salta, também, aos olhos. E é nesse último que nos deteremos no decorrer da análise.

As duas primeiras estrofes apresentam paralelismo construído basicamente pelo advérbio "quando", que se refere tanto a um tempo como também a uma condição. Nesse caso a condição estabelece um momento em que o eu lírico abandonará o silêncio e abrirá o canal para o diálogo.

Há, portanto, implicado na palavra "Silence", uma indicação de mudez, mas no desenvolver do poema, os elementos que podem possibilitar um diálogo se multiplicam na intenção deixar claras todas as condições favoráveis para sua erupção. Por isso, a palavra "quando", recorrente em nove dos quinze versos das duas primeiras estrofes e subentendida nos demais pelo uso do conectivo " $\mathrm{e}$ ", está atrelada não somente ao tempo, mas a uma condição.

O eu poeta condiciona a quebra do silêncio a algumas situações. Essa insistência ou ênfase fica marcada pela repetição, pelo paralelismo na primeira e na segunda estrofes. O paralelismo sintático evidencia o conteúdo do enunciado e aponta para as instâncias significativas do sentido poético. Segundo Micheletti, "[...] a repetição em geral é apontada como intensificadora de determinado traço criando expectativa e tensão. Mais que expectativa e tensão ela gera o próprio significado" (MICHELETTI, 1997 p.158).

Nesse paralelismo que se estrutura, basicamente, a partir do conectivo "quando" seguido por um verbo no infinitivo, verifica-se que a construção se esteia no futuro do subjuntivo, o que lança para além a possibilidade do diálogo, construindo o sentido de uma condição a ser observada.

Pelos sons que constituem o conectivo "quando", nota-se que, além de marcar um ritmo constante, semelhante a um coração que pulsa, também sugere um movimento, de abertura e fechamento, reverberando um eco interno. Ao desmembrarmos a palavra, verificamos na sílaba inicial /kuã/ uma certa abertura e prolongamento e, na final /-du/, um corte mais brusco, um fechamento. Ou seja, som de abertura da palavra, evocada pela surda / $/$ / sugere uma batida mais forte, o fonema da nasal /ã/, prolonga esse som que é seguido por uma oclusiva /d/, combinada à vogal /o/, cujo som indica, segundo Martins, a ideia de fechamento (2012, p.52). Não nos deteremos nos aspectos sonoros, mas há, nitidamente, um ritmo ascendente nos versos da primeira estrofe que se altera no verso final, "conversaremos".

Há, nesse último verso, a indicação de que o silêncio será rompido, mas nada fica assegurado, pois o enunciador projeta algo em um tempo no futuro, mas não há como sustentar que esses eventos realmente acontecerão. Há, no advérbio, a incerteza quanto ao tempo, uma vez que está condicionado a algumas circunstâncias que podem ou não serem satisfeitas.

Como já assinalamos, a expressão formada por "quando" mais o verbo ("quando disparar", "quando pernoitar", "quando [...] faltarem, "quando despertarem", "quando [...] ficarem", "quando [...] reservar", "quando [...] exigir", "quando [...] vier", "quando fizermos") constituem o que a Gramática caracteriza como futuro do subjuntivo, que indica uma ação que se configura como expectativa; Bechara afirma que o subjuntivo é utilizado "para exprimir hipótese, e não uma realidade" (2009, p.238), portanto trata-se de uma possibilidade de acontecer ou não. 
Assim, optamos por centrar nosso olhar e interpretação nos versos que contemplam as condições apresentadas pelo eu lírico e demais desdobramentos que surgem a partir delas. Destacaremos cada uma das circunstâncias que o enunciador elenca para que possa quebrar o silêncio.

$1^{\text {a. }}$ Circunstância: "Quando disparar no peito o ritmo dos séculos".

A ideia que advém do verbo disparar é a de começar, como em uma corrida, em que o árbitro dá o tiro de início da competição. Nesse verso, o enunciador se refere ao disparo do ritmo dos séculos. Ritmo diz respeito à constância, compasso, regularidade. Esse verbo evoca a natureza dessa velocidade que se dá em um determinado instante, algo/ alguém que sai do estado de descanso ou lentidão para a ação veloz.

O sujeito poético determina um lugar para "o ritmo do século" disparar, o peito, metonímia que representa o corpo, a pessoa, o ser humano. Em geral, pelo senso comum, a referência a "peito", trata de força e coragem. No peito está um coração que pulsa e cuja vitalidade se verifica no ritmo dos batimentos, conforme já mencionamos. O coração movimenta-se em batidas regulares, mas o sujeito poético espera que ele "dispare", que seja propelido à sequência harmônica dos séculos, que haja uma mudança de ritmo, pois o "disparo" está atrelado a uma aceleração, ao aumento da velocidade.

Como já assinalamos, o ritmo está ligado a compasso, movimento que ocorre com constância, alternâncias regulares, sem ruptura. Em se tratando dos séculos, é possível inferir que o tempo, ou seu decurso segue ininterruptamente, e que o sujeito poético pretende que esse tempo venha em um ritmo acelerado.

Nesse primeiro verso, o sujeito poético lança luz sobre a questão do tempo e da velocidade. Ele estabelece não apenas um momento para alcançar velocidade, mas foca um nível de ação. Nele, que traz uma condição, o tempo é apontado como um condutor de fatos, pois "o ritmo dos séculos", é o sujeito da ação. E, nessa condição estabelecida, o sujeito poético não focaliza o fim, mas o começo. Em "disparar" encontramos dois dos significados da palavra: o início de algo como também um ritmo acelerado, ambos contemplados no poema.

2a. Circunstância: "Quando pernoitar nos olhos um galo e sua aurora".

Tem-se, nesse segundo verso, o início de um paralelismo que estruturará as duas primeiras estrofes. Novamente a presença do verbo no futuro do subjuntivo, mais o corpo metonimicamente representado pelos "olhos". Nesse verso o eu lírico espera que haja "nos olhos um galo e sua aurora" o que, juntamente com os demais elementos do verso, sugere a recorrência de algo que marca a passagem do tempo.

Considerando que "galo" seja o sujeito da oração, nossa atenção se volta para a postura desse ser, o que se espera dele. Nesse caso, o foco da ação está no pernoitar, permanecer "nos olhos". Há uma combinação de sensações auditivas e visuais na junção desses dois versos iniciais: "ritmo dos séculos" dispara e o "galo" canta anunciando o alvorecer, o nascer do sol, indicando que a noite se foi e um novo dia começa. Destacamos que o "peito" e os "olhos" são do enunciador que, no verso seguinte, se apresenta na forma verbal de "escondemos".

3a. Circunstância: "Quando todavia nos faltarem copos e garrafas". 
Nesse verso, o destaque não está mais no processo, mas no agente, ou melhor, nos agentes: o Eu lírico mais o Tu, alguém com quem ele busca dialogar. A presença da conjunção "todavia" marca a adversidade em relação aos sentidos dos versos anteriores. No poema, não se elucida a presença desses "copos e garrafas", há vazios interpretativos que devem ser preenchidos pelo leitor na sua relação com o texto. Entretanto, fica marcada a presença de um eu e um tu, no pronome "nos".

O enunciador enfatiza o tempo ou a condição, por isso, o destaque para "todavia" se insere no fato de que, à primeira vista, parece tratar-se de uma conjunção adversativa, porém, Bechara indica outra possibilidade para o conectivo, assinalando uma relação semântica com o que foi dito,

Levada pelo aspecto de certa proximidade de equivalência semântica, a tradição gramatical tem incluído entre as conjunções coordenativas certos advérbios que estabelecem relações interoracionais ou intertextuais. É o caso de [...], todavia. (BECHARA, E. 2009, p. 270)

A partir da explicação de Bechara, podemos pensar em "todavia" como sinônimo de "também", lembrando que nenhuma palavra equivale exatamente a outra e cada escolha representa uma necessidade expressiva. Sem buscar parafrasear o que afirma o enunciador, salientamos que é mais um elemento que constitui um cenário e o decorrer do tempo.

É possível interpretar essa falta "de copos e garrafas" como algo que se tenha esgotado para atingir o modo de ser ou estar em que deverão encontrar-se os participantes do possível diálogo, como descrito no sexto verso.

Não há espaço para o improviso, o enunciador vislumbra um cenário em que o diálogo necessita não apenas do momento certo, mas também de elementos que supram algumas necessidades físicas, assim como é mister ao homem comunicar, é também de se alimentar.

4a. Circunstância: "Quando despertarem as pedras que escondemos nas mãos".

Em geral, atribui-se às mãos as ações do fazer. No verso em questão, as pedras dormem, escondidas, numa postura silenciosa, inertes, "nas mãos". As pedras estão personificadas, pois dormem, estão quietas. É interessante ponderar que há algo escondido e que, pela construção de tom assertivo, sugere-se uma consciência do enunciador sobre as pedras e seus propósitos. É possível que esteja, nesse verso, uma antecipação do que se pretende: "erigiremos estátuas".

\section{5a. Circunstância: "Quando o estado em mim, das coisas e dos ritos}

em ti, bovinamente, em geral ficarem",

Nesses dois versos, o enunciador que já mencionara o outro nos versos anteriores ("nos" e "escondemos") busca transferir para seu (sua) possível interlocutor(a) aquilo que está nele, "coisas", "ritos", "bovinamente". Nota-se o desdobrar-se em "mim" e "ti". Trata-se, inclusive, de um estado que se pretende permanente, expresso no verbo "ficarem". Há uma certa dose de aceitação na medida em que o advérbio remete à resignação, à paciência.

Só então, quando "as coisas... ficarem" o enunciador conclui que será possível: "conversaremos'. Ou seja, somente depois de satisfeitas essas exigências, o silêncio será rompido e eles poderão trocar palavras. 
Após elencar todas essas condições, tem-se uma pausa, representada pela mudança de estrofe, entretanto o diálogo, ainda não será possível, uma vez que as condições continuam a serem registradas. Interessa notar que, nas condições apresentadas, permanece uma descrição a partir da metonímia. Antes, "peito", "olhos", "mãos"; agora, "sangue", "veias", "coração" e a própria "respiração".

Como o diálogo, a quebra do silêncio, não aconteceu, segue-se então a voz do sujeito poético que retoma as palavras, colocando condições, outras circunstâncias, para calar o silêncio.

Acompanhando a segunda estrofe:

6a. Circunstância "Quando o sangue reservar o corpo todo"

Nesse ponto do poema, o enunciador traz o sangue, elemento que flui pelo corpo todo. Considerando que o sangue denota vida, vigor, o eu sujeito espera que ele permeie todo o sistema. É preciso que haja a participação de todo o ser, o sangue reserva não apenas partes, mas a totalidade. $\mathrm{A}$ vitalidade vinda do sangue deve estar em todos os sentidos do homem, órgãos, músculos e assim por diante.

A acepção de "reservar" pode estar ligada a estocar para distribuir, esse entendimento se esclarece ao lermos os versos seguintes:

\section{7a. Circunstância:}

"Quando a ferrugem das veias exigir mais tempo

$$
\text { e o rio de nós engordar o coração e o chão }
$$

de todas as coisas não for pisado novamente"

Registramos como 7a. circunstância, baseados tão somente no início dos versos, mas é preciso notar que dela (circunstância) decorrem duas outras associadas pelo conectivo "e", aspecto já mencionado, constituindo uma espécie de desdobramento e expansão.

A "ferrugem das veias" sugere a passagem de um tempo que trouxe desgaste ao ser, mas que pode ser, regenerado pelo "sangue" mencionado no primeiro verso da estrofe, ainda que possa "exigir mais tempo". Como em todo o poema, há o predomínio de uma linguagem figurada que necessita de um leitor mais atento e perspicaz. Juntamente com a metonímia, já destacada por nós, a metáfora ocupa um papel de destaque na composição: há "veias enferrujadas", mas existe, também, um "rio de nós" que responde pela circulação, pela palavra capaz de romper o silêncio.

O "rio de nós" figura o sangue que percorre as veias (os canais), o rio que o enunciador associa a "nós". O (a) interlocutor(a) com quem o eu trocou "coisas e ritos" continua junto e, mais fortemente, na medida em que é o sangue que os une.

A ideia de movimento e vitalidade é recorrente neste poema, o rio é água em movimento. Considerando que este rio é o sangue que corre nas veias, ele conduz à vida, de modo especial "em nós", sujeito e seu (sua) interlocutor(a).

Esse rio vai "engordar" o coração e o chão. O verbo "engordar" denota a ação que visa a alimentação, nutrição de modo pleno. O sangue tem a atribuição de suster e "engordar", e o sujeito poético indica, nesse verso, quais entes serão beneficiados: "coração e o chão"

É possível atribuir ao coração, as emoções e ao chão, a realidade, algo que está do lado de fora, sugerindo que o eu lírico deseja estar, fortalecido, não apenas interiormente, com as emoções, mas 
também na esfera da vida externa. Trata-se de uma referência à totalidade, "(...) e o chão / de todas as coisas não for pisado novamente".

8a. Circunstância: "Quando o ócio dos nocautes vier em chuva e enxurrada

e a própria chuva rir e dividir o nosso nada"

Como no bloco anterior, essa circunstância se amplia. É de se notar não apenas esse desdobramento. Na primeira estrofe, cada circunstância, quase todas, se limitavam a um único verso; na segunda, são precisos dois ou três. Ocorre, assim, uma espécie de amplificação. Essa amplificação, marcada pela presença do conectivo " $\mathrm{e}$ ", traz acréscimos; de certo modo, multiplicando as condições que continuam a ser registradas.

A expressão "ócio dos nocautes" revela uma impossibilidade de ação, na medida em que o primeiro elemento marca um não fazer diante de uma incisiva derrota. Há uma intensificação que emerge da expressão "vier em chuva e enxurrada", ou seja, a possibilidade de permanência é praticamente nula, conforme o verso "e a própria chuva rir e dividir o nosso nada".

A análise e interpretação tem-se detido, basicamente, em questões semânticas, mas cabe voltar a um aspecto do poema que corrobora, pela sugestão sonora, as observações anteriores. Nota-se um alongamento "em chuva e enxurrada" que converge na rima "nada", presente num verso marcado pela estridência do fonema vocálico /i/.

Em seguida, pela prosopopeia, a chuva volta, desta vez com ações humanas, "rir e dividir o nosso nada". As palavras do eu lírico acusam a enxurrada de ter levado coisas, como em uma enchente que faz submergir o que está em seu caminho. "O ócio dos nocautes" carregará, com a chuva e a enxurrada, "o nada" que pertence ao enunciador e a seu (sua) interlocutor(a). Em "dividir o nosso nada", ainda que "nada" possa significar coisa nenhuma, se constata que eles compartilham algo que parece uni-los.

Segue-se a isso a última circunstância apontada pelo sujeito poético que, a essa altura, já não demonstra uma imposição como em versos anteriores, mas percepção do que está por vir, como um evento do qual não pode esquivar-se.

\section{9a. Circunstância}

"Quando fizermos epígrafes para os tontos e conspirarmos contra a respiração dos muros"

Os dois versos que constituem essa condição estão ligados pela conjunção coordenada aditiva " $\mathrm{e}$ ", aparentemente os fatos neles mencionados não têm relação, mas, além do elo promovido pela conjunção, as ideias se completam.

As epígrafes são textos colocados em destaque, geralmente na abertura de livros e/ou capítulos. No poema a palavra adquire um sentido de dedicatórias a serem feitas "para os tontos". Ao fazê-las aos tontos, o enunciador parece referir-se a uma expressão inútil, porque a palavra "tontos" remete a seres simplórios que, possivelmente, não poderiam compreender o alcance de suas conjecturas. No segundo verso, quando o sujeito poético especula "conspirar", podemos deduzir que esses "muros", figuram seres ou situações que deverão ser neutralizadas.

As duas próximas estrofes não se apresentam mais com o conectivo "quando", mas a terceira se inicia pela conjunção " $e$ ", remetendo à condição expressa na estrofe anterior. Assim, corresponde a um 
acréscimo às condições anteriores, numa forma progressiva: "respiração dos muros", com a dureza e impenetrabilidade que os caracteriza, e "fôlego das nuvens / e das águas", elementos que se desfazem e se esvaem, num juntar de elementos aparentemente contrários.

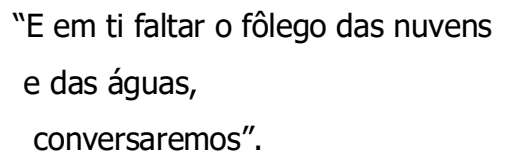

Nesses versos, o sujeito poético se dirige a seu (sua) interlocutor(a), como já o fizera no penúltimo verso da primeira estrofe, atribuindo-lhe um estado que se fará necessário para a quebra do silêncio. Fica uma sugestão de que, quando a resistência for rompida, "conversaremos", o diálogo far-se-á possível.

Ao juntarmos o exposto em ambos os versos, percebemos que eles apontam para o mesmo sentido, ou seja, o sujeito poético espera que o outro desarme-se "bovinamente" e deixe de resistir. Para ele, somente com esse estado de espírito as condições de um diálogo serão favoráveis.

O enunciador completa a terceira estrofe com "conversaremos". Nesse ponto, é importante notar que apenas dois verbos ("conversaremos" e "erigiremos") encontram-se em orações principais, todos os demais estão em orações adverbiais marcando circunstâncias. A oração principal é aquela que, no discurso, traz a ideia central do pensamento que está expresso. Na estrofe seguinte, encontra-se a forma "erigiremos"

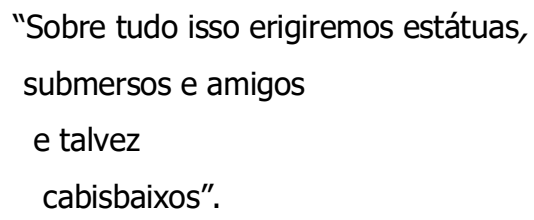

Estátuas são construídas para marcar momentos na história, homenagear pessoas. Elas contam às gerações e comunidades que vão surgindo os momentos da vida de um povo, suas histórias, tradições, feitos, enfim. Em "erigiremos estátuas" figura-se a possibilidade, por fim, do diálogo e da ruptura com o silêncio. Ainda que o verbo se apresente no presente do indicativo, um modo assertivo, o que indica a possibilidade reside na construção das estrofes anteriores, cunhadas em circunstâncias.

\section{Considerações finais}

Em nossos apontamentos sobre "Silence", acentuamos os aspectos lexicais, ainda que notássemos aspectos rítmicos que também poderiam ser explorados pela análise. É um poema que se vale de uma linguagem figurada, basicamente metonímias e metáforas que constroem relação entre fala (som) e silêncio. Há, como registramos ao longo da análise, uma enumeração de várias circunstâncias que se apresentam numa estrutura paralelística que enfatiza uma busca empreendida pelo sujeito poético. 
O silêncio é o ponto de partida para uma reflexão sobre o diálogo, todo o discurso está voltado para essa reflexão sobre a condição humana. Ou se fala, ou se cala; ou o som ou o silêncio, ainda que este provoque rumores no interior de cada ser, como no enunciador de "Silence".

$\mathrm{Na}$ introdução fizemos referência ao contexto desse poema que se encontra no conjunto a que denominou "Garganta didática" que, por sua vez, está em "Revelações do Abismo", parte que compõem Vastafala. Fala e silêncio são dois estados ou circunstâncias permanentes, tratados em "Silence" por uma voz ("garganta") que se pretende didática.

As pseudo revelações nascem de um processo de introspecção, de uma busca interior que procura, de certa forma, problematizar algo que está além da compreensão do eu que se expressa e compartilha com o outro sua inquietação.

O poema traz de modo cifrado uma dualidade que perpassa a existência, vai além do diálogo entre duas pessoas históricas, mas trata dele enquanto essas pessoas sejam inominadas, apontado para algo que é eterno. Lembra, de imediato, Drummond (1988, 256-257) em seu poema "Eterno" no qual, na terceira estrofe, encontramos uma referência a Pascal (Le silence éternel de ces espaces infinis m'effraie) em que o peso do silêncio o faz refletir e o assusta. É o que se pode surpreender.

\section{Referências:}

ANDRADE, C. D. Poesia e Prosa. 6 ed. R. de Janeiro. Nova Aguilar, 1988.

BARRETO, A. Vastafala. São Paulo. Scipione, 1988

BECHARA, E. Moderna Gramática Portuguesa. 37a. ed. Rio de Janeiro: Nova Fronteira, 2009.

GARCIA, O. M.. Comunicação em Prosa Moderna. São Paulo: FGV, 2011

MARTINS, N. S. Introdução à Estilistica. 4a. ed. São Paulo: Edusp, 2012.

MICHELETTI, G. Estilística, Um Modo de Ler Poesia. 2a. ed. São Paulo: Andross, 2006.

. Repetição e Significado Poético. Filologia e Linguística Portuguesa, n.1, p. 151-164, 1977

ORLANDI, E. As formas do silêncio. 4a reimpressão. São Paulo: UNICAMP,. 2015

SPARANO, M. Subjetividade e Discurso: Os Aspectos Gramaticais na Poesia. In: SPARANO, M., VARGAS, M. (org) Enunciação, Subjetividade e Práticas de Linguagem: Revisitando Beveniste. São Paulo: Paulistana, 2011. 